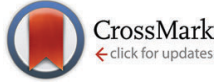

Cite this: Phys. Chem. Chem. Phys., $2016,18,23528$

Received 16th May 2016, Accepted 29th July 2016

DOI: $10.1039 / c 6 c p 03324 e$

www.rsc.org/pccp

\title{
Charge transfer reactions between gas-phase hydrated electrons, molecular oxygen and carbon dioxide at temperatures of $80-300 \mathrm{~K} \dagger$
}

\author{
Amou Akhgarnusch, ${ }^{\text {ab }}$ Wai Kit Tang, ${ }^{c}$ Han Zhang, $\ddagger^{c}$ Chi-Kit Siu*c and \\ Martin K. Beyer*ab
}

\begin{abstract}
The recombination reactions of gas-phase hydrated electrons $\left(\mathrm{H}_{2} \mathrm{O}\right)_{n}{ }^{\bullet-}$ with $\mathrm{CO}_{2}$ and $\mathrm{O}_{2}$, as well as the charge exchange reaction of $\mathrm{CO}_{2}{ }^{\bullet-}\left(\mathrm{H}_{2} \mathrm{O}\right)_{n}$ with $\mathrm{O}_{2}$, were studied by Fourier transform ion cyclotron resonance (FT-ICR) mass spectrometry in the temperature range $T=80-300 \mathrm{~K}$. Comparison of the rate constants with collision models shows that $\mathrm{CO}_{2}$ reacts with $50 \%$ collision efficiency, while $\mathrm{O}_{2}$ reacts considerably slower. Nanocalorimetry yields internally consistent results for the three reactions. Converted to room temperature condensed phase, this yields hydration enthalpies of $\mathrm{CO}_{2}{ }^{--}$and $\mathrm{O}_{2}{ }^{\bullet-}$, $\Delta H_{\text {hyd }}\left(\mathrm{CO}_{2}{ }^{--}\right)=-334 \pm 44 \mathrm{~kJ} \mathrm{~mol}^{-1}$ and $\Delta H_{\text {hyd }}\left(\mathrm{O}_{2}{ }^{\bullet-}\right)=-404 \pm 28 \mathrm{~kJ} \mathrm{~mol}^{-1}$. Quantum chemical calculations show that the charge exchange reaction proceeds via a $\mathrm{CO}_{4}{ }^{--}$intermediate, which is consistent with a fully ergodic reaction and also with the small efficiency. Ab initio molecular dynamics simulations corroborate this picture and indicate that the $\mathrm{CO}_{4}{ }^{\bullet-}$ intermediate has a lifetime significantly above the ps regime.
\end{abstract}

\section{Introduction}

Hydrated electrons in the gas phase ${ }^{1-3}$ have been known for more than 30 years. Today they are very well characterized spectroscopically. ${ }^{4-16}$ Even the dynamics following photoexcitation have been revealed recently. ${ }^{17,18}$ Clusters also serve as model systems for the hydrated electron inside bulk water or on its surface. ${ }^{19,20}$ Thermochemical information can be inferred from the number of water molecules evaporating during the reaction. ${ }^{21-24}$ Williams and coworkers use this concept of nanocalorimetry to

\footnotetext{
${ }^{a}$ Institut für Physikalische Chemie, Christian-Albrechts-Universität zu Kiel, Olshausenstrasse 40, 24098 Kiel, Germany

${ }^{b}$ Institut für Ionenphysik und Angewandte Physik, Leopold-Franzens-Universität Innsbruck, Technikerstrasse 25, 6020 Innsbruck, Austria.

E-mail:martin.beyer@uibk.ac.at

${ }^{c}$ Department of Biology and Chemistry, City University of Hong Kong, 83 Tat Chee Avenue, Kowloon Tong, Hong Kong SAR, P. R. China. E-mail: chiksiu@cityu.edu.hk $\dagger$ Electronic supplementary information (ESI) available: Details on the conversion from $\Delta E_{\text {raw }}$ to $\Delta H_{298 \mathrm{~K}}$. Mass spectra, fits and rates for reactions (4) and (5). Analysis of the quartet and doublet potential energy surface crossing of $\mathrm{CO}_{4}{ }^{-}\left(\mathrm{H}_{2} \mathrm{O}\right)_{5}$. Additional relative energies of $\mathrm{CO}_{2}{ }^{--}\left(\mathrm{H}_{2} \mathrm{O}\right)_{10}$ for optimized structures. Geometries for the exchange reaction $\mathrm{CO}_{2}{ }^{-}-\left(\mathrm{H}_{2} \mathrm{O}\right)_{10}+\mathrm{O}_{2} \rightarrow \mathrm{O}_{2}{ }^{-}-\left(\mathrm{H}_{2} \mathrm{O}\right)_{10}+$ $\mathrm{CO}_{2}$. Additional trajectories under the $N V E$ and $N V T$ conditions. Cartesian coordinates for all reported structures. Movies for one $N V E$ and one $N V T$ trajectory. See DOI: 10.1039/c6cp03324e

\# Current address: Laboratory of New Fiber Materials and Modern Textile, Growing Base for State Key Laboratory, Qingdao University, 308 Ningxia Road, Qingdao, 266071, P. R. China.
}

perform electrochemical measurements directly in the gas phase, using multiply charged hydrated cations recombining with free electrons. $^{25,26}$

We have recently established a variant of nanocalorimetry which allows us to measure the thermochemistry of ion-molecule reactions of hydrated ions in a Fourier transform ion cyclotron resonance (FT-ICR) mass spectrometer. ${ }^{24}$ We have tested this method for a series of reactions with hydrated electrons, ${ }^{27-29}$ the carbon dioxide radical anion, ${ }^{30-32}$ and hydrated metal ions. ${ }^{33-35}$ For hydrated electrons and the carbon dioxide radical anion, the method seems to work very well. Hydrated metal ions, on the other hand, often exhibit a very pronounced size dependence, which compromises the results of nanocalorimetry. For accurate results, three conditions must be fulfilled: (A) the reaction rate must be independent from cluster size, (B) the reaction rate must be independent from the internal energy content of the cluster, and $(\mathrm{C})$ the reaction must be fully ergodic, i.e. the energy released during the reaction must be statistically distributed over all internal degrees of freedom of the water cluster.

In our initial work on nanocalorimetry, ${ }^{24}$ reactions of hydrated electrons $\left(\mathrm{H}_{2} \mathrm{O}\right)_{n}{ }^{\bullet-}$ with $\mathrm{CO}_{2}$ and $\mathrm{O}_{2}$ as well as the core-switching reaction of $\mathrm{CO}_{2}{ }^{\bullet-}\left(\mathrm{H}_{2} \mathrm{O}\right)_{n}$ with $\mathrm{O}_{2}$ were studied. Based on the results, the ergodicity assumption was questioned for the core switching reaction, implying a direct charge transfer from $\mathrm{CO}_{2}{ }^{\bullet-}$ to $\mathrm{O}_{2}$ resulting in the formation of superoxide. In a recent review, however, Weber pointed out that due to the strong interaction between $\mathrm{CO}_{2}$ and superoxide, it is very 
likely that the charge transfer involves $\mathrm{CO}_{4}{ }^{--}$as an intermediate. Formation of this intermediate, however, implies that the charge transfer proceeds while there is strong coupling of the $\mathrm{CO}_{2}$ unit to the water cluster, while the non-ergodic picture put forward in our previous study implies that neutral $\mathrm{CO}_{2}$ is formed in the bent geometry of the anion, and would be evaporated vibrationally excited. In a nutshell, the presence of the $\mathrm{CO}_{4}{ }^{--}$intermediate means that the reaction is fully ergodic, in contrast to the conclusions from our previous study. ${ }^{24}$ This discrepancy prompted us to repeat the experiments with $\left(\mathrm{H}_{2} \mathrm{O}\right)_{n}{ }^{\bullet-}$ reacting with $\mathrm{CO}_{2}$ and $\mathrm{O}_{2}$, as well as $\mathrm{CO}_{2}{ }^{\bullet-}\left(\mathrm{H}_{2} \mathrm{O}\right)_{n}$ reacting with $\mathrm{O}_{2}$, to get more precise values for the hydration enthalpy of the product species and to check whether the release of $\mathrm{CO}_{2}$ in the core switching reaction is ergodic or not, condition (C). Starting with different initial cluster size distributions and working at different temperatures, we should also be able to test the validity of conditions (A) and (B). The insight gained from the size and temperature dependent experiments significantly enhances our understanding of the reaction dynamics of large water clusters.

\section{Experimental}

The experiments are conducted on a modified Bruker/Spectrospin CMS47X FT-ICR mass spectrometer, equipped with a $4.7 \mathrm{~T}$ superconducting magnet, Bruker infinity cell modified to allow liquid nitrogen cooling, and APEX III data station. ${ }^{24,36-39}$ The hydrated ion clusters are generated in an external laser vaporization source $^{40-42}$ as described previously. ${ }^{24}$ The hydrated anions are stored in the ICR cell with a base pressure below $5 \times 10^{-10} \mathrm{mbar}$. Reactants are introduced into the UHV region through a needle valve at constant pressures between $5.0 \times 10^{-9}$ and $1.0 \times$ $10^{-8}$ mbar. Reactions are monitored by measuring mass spectra as a function of time. Pressure calibration and calculation of absolute rate constants was done following established procedures. $^{29,43}$

The average cluster size $N_{\mathrm{R}}$ and $N_{\mathrm{P}}$ of reactant and product species, respectively, is calculated from these data. To extract thermochemical information, these values are fitted with a genetic algorithm with a set of differential equations:

$$
\begin{gathered}
\mathrm{d} N_{\mathrm{R}}=-k_{\mathrm{f}}\left(N_{\mathrm{R}}-N_{0, \mathrm{R}}\right) \mathrm{d} t \\
\mathrm{~d} N_{\mathrm{P}}=-k_{\mathrm{f}}\left(N_{\mathrm{P}}-N_{0, \mathrm{P}}\right) \mathrm{d} t+\left(N_{\mathrm{R}}-\Delta N_{\text {vap }}-N_{\mathrm{P}}\right)\left(k I_{\mathrm{R}} / I_{\mathrm{P}}\right) \mathrm{d} t
\end{gathered}
$$

Eqn (1) and the first term in eqn (2) account for black-body radiation induced dissociation (BIRD) of water clusters, ${ }^{4-50}$ where $k_{\mathrm{f}}$ describes the linear dependence of the BIRD rate on cluster size. $N_{0, \mathrm{R}}, N_{0, \mathrm{P}}$ correct for the contribution of the ionic core to the infrared absorption cross sections. The second term in eqn (2) deals with the bimolecular reaction, describing the evaporation of water molecules due to the reaction enthalpy released in the cluster. Key result of the fit is the average

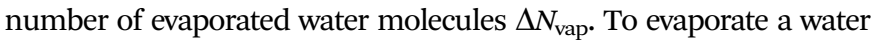
molecule from the cluster, the energy $\Delta E_{\mathrm{vap}}=43.3 \pm 3.1 \mathrm{~kJ} \mathrm{~mol}^{-1}$ is required. This value has been measured by photodissociation. ${ }^{51,52}$ With our original fit procedure, convergence was reached only if one fit parameter was kept constant. ${ }^{24}$ With our recent modification, this is no longer necessary. ${ }^{29}$ Now the average cluster size as well as the difference in cluster size are fitted over the full time range, and their contribution to the total error can be adjusted with a weight parameter. Convergence of the fits is thus achieved with all fit parameters active. The heat released in the cluster during the reaction can be calculated directly with $\Delta E_{\text {raw }}=-\Delta N_{\text {vap }} \Delta E_{\text {vap. }}{ }^{53}$

Quantum chemical calculations were performed with density functional theory at the M06-2X/6-311++G(d,p) level using the Gaussian09 suite of program. ${ }^{54}$ All energies were corrected with zero-point energy obtained from harmonic vibration analyses. Local minima and transition structures on the potential energy surface were confirmed with no and one imaginary frequency, respectively. The local minima structures associated with each transition structure were verified by the intrinsic reaction coordination method. Spin density distributions were evaluated at the same level of theory and shown using an isosurface with a value of 0.02 au.

Molecular dynamics simulations were performed with density functional theory at the revPBE level using the Quickstep module of the CP2K suite of programs. ${ }^{55}$ A triple-zeta Gaussian basis set augmented with diffuse functions plus the Goedecker-TeterHutter pseudopotential (with charge density cutoff of $280 \mathrm{Ry}$ ) for an auxiliary planewave basis set (TZV2P-MOLOPT-GTH) were used. ${ }^{56,57}$ Dispersion interaction was corrected with the Grimme D3 method (with Becke-Johnson damping). ${ }^{58-60}$ The chemical systems were placed at the center of a cubic simulation box with the lattice parameters of $18 \times 18 \times 18 \AA^{3}$, corrected with the Martyna and Tuckerman Poisson solver. ${ }^{61}$ Equations of motion of the classical Newtonian mechanics for all atoms were integrated with a time step of 0.5 fs under either the micro-canonical ensemble $(N V E)$ conditions or the canonical ensemble (NVT) conditions with the constant temperatures controlled by NoséHoover thermostats. ${ }^{62}$

\section{Results and discussion}

\section{Experimental results}

Mass spectra of the reaction of $\left(\mathrm{H}_{2} \mathrm{O}\right)_{n}{ }^{\bullet-}$ with $\mathrm{CO}_{2}$ at a temperature of $226 \pm 2 \mathrm{~K}$ and a $\mathrm{CO}_{2}$ pressure of $6.0 \times 10^{-9}$ mbar are shown in Fig. 1. One molecule of $\mathrm{CO}_{2}$ is quantitatively taken up by hydrated electrons, reaction (3).

$$
\left(\mathrm{H}_{2} \mathrm{O}\right)_{n}^{\bullet-}+\mathrm{CO}_{2} \rightarrow \mathrm{CO}_{2}^{\bullet-}\left(\mathrm{H}_{2} \mathrm{O}\right)_{n-m}+m \mathrm{H}_{2} \mathrm{O}
$$

Due to the low temperature, the rate of BIRD is significantly reduced, and the cluster size distribution shifts only very slowly to smaller sizes with increasing reaction delay. Fig. 2 shows the reaction kinetics and the nanocalorimetric fit for this experiment, for reaction delays up to $3 \mathrm{~s}$. The kinetics clearly exhibits pseudofirst order behavior. A fit of the average cluster sizes and their difference with eqn (1) and (2) works very well and yields $\Delta N_{\text {vap,226K }}(3)=2.2$ water molecules.

We repeated the experiment at temperatures from $130 \mathrm{~K}$ to $298 \mathrm{~K}$. Below $160 \mathrm{~K}$, it became difficult to stabilize the $\mathrm{CO}_{2}$ 


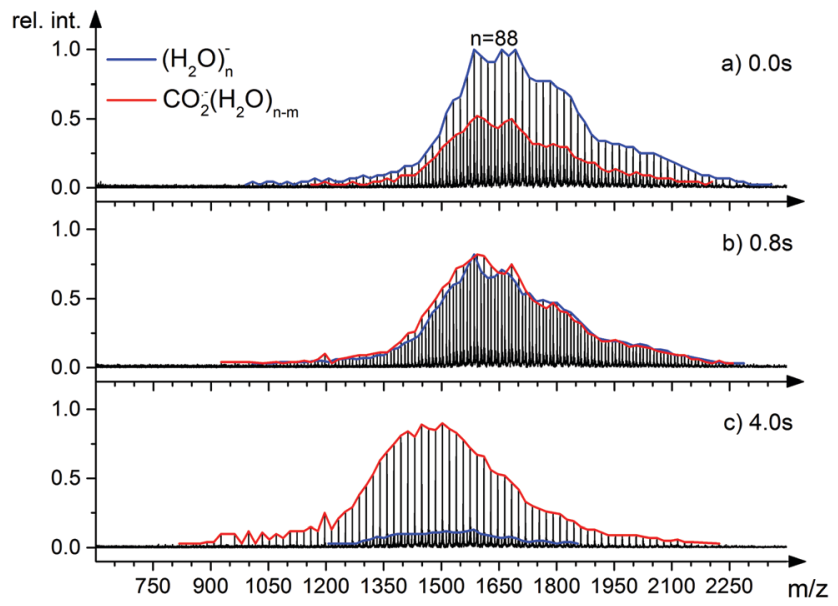

Fig. 1 Mass spectra of the reaction $\left(\mathrm{H}_{2} \mathrm{O}\right)_{n^{-}}{ }^{-}$with $\mathrm{CO}_{2}$ at a temperature of $226 \pm 2 \mathrm{~K}$ and $\mathrm{a} \mathrm{CO}_{2}$ pressure of $6.0 \times 10^{-9} \mathrm{mbar}$ after nominal (a) $0 \mathrm{~s}$, (b) $0.8 \mathrm{~s}$, and (c) $4.0 \mathrm{~s}$ reaction delay.

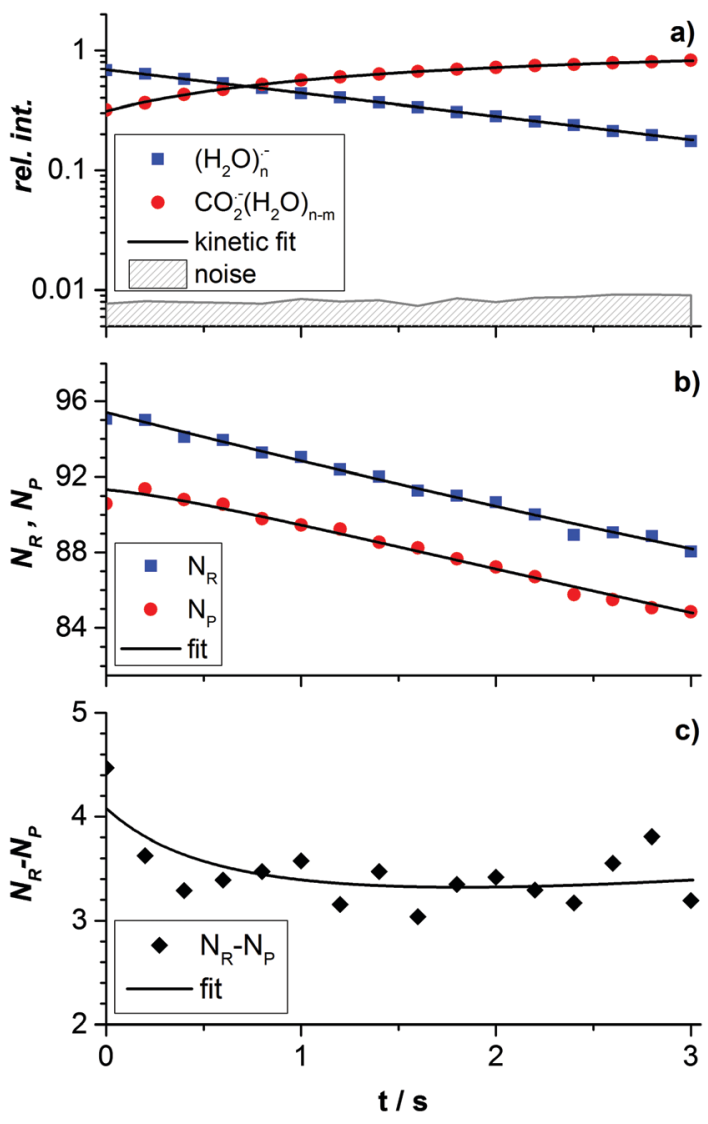

Fig. 2 (a) Kinetics and (b), (c) nanocalorimetric fits of the reaction of $\left(\mathrm{H}_{2} \mathrm{O}\right)_{n}{ }^{\bullet-}$ with $\mathrm{CO}_{2}$ at $T=226 \pm 2 \mathrm{~K}$ and $p=6.0 \times 10^{-9} \mathrm{mbar}$, see Fig. 1 . Blue filled squares, $\left(\mathrm{H}_{2} \mathrm{O}\right)_{n}{ }^{--}$; red filled circle, $\mathrm{CO}_{2} \cdot{ }^{-}\left(\mathrm{H}_{2} \mathrm{O}\right)_{n-m i}$ filled diamond, difference in the cluster size.

pressure in the ICR cell, indicating that the reaction gas started to freeze out on the surfaces. As a consequence, the data sets exhibit a larger scattering of data points at low temperatures for $\mathrm{CO}_{2}$. The results of the kinetic and nanocalorimetric fits are summarized in Table 1 . Interestingly, the absolute rate
Table 1 Initial cluster size range, temperature, reactant gas pressure, relative and absolute rate constants $k_{\text {rel }}$ and $k_{\text {abs }}$, respectively, and average number of evaporated water molecules $\Delta \mathrm{N}_{\text {vap }}$ for the reaction of $\left(\mathrm{H}_{2} \mathrm{O}\right)_{n}{ }^{\bullet-}$ with $\mathrm{CO}_{2}$

\begin{tabular}{llllll}
\hline $\mathrm{CO}_{2}+\left(\mathrm{H}_{2} \mathrm{O}\right)_{n}^{\bullet-}$ & $T / \mathrm{K}$ & $p_{\mathrm{m}} / 10^{-9} \mathrm{mbar}$ & $k_{\mathrm{rel}} / \mathrm{s}^{-1}$ & $k_{\mathrm{abs}} / 10^{-10} \mathrm{~cm}^{3} \mathrm{~s}^{-1}$ & $\Delta N_{\text {vap }}$ \\
\hline$n=62-130$ & 298 & 2.8 & 0.20 & 10.7 & 2.7 \\
$n=61-134$ & 298 & 6.4 & 0.43 & 10.0 & 3.4 \\
$n=40-92$ & 298 & 6.0 & 0.37 & 9.2 & 2.3 \\
$n=38-95$ & 298 & 9.5 & 0.58 & 9.2 & 2.4 \\
$n=42-107$ & 298 & 5.8 & 0.35 & 9.2 & 2.1 \\
$n=64-130$ & 266 & 4.2 & 0.23 & 7.4 & 2.5 \\
$n=58-132$ & 266 & 4.5 & 0.23 & 7.0 & 2.1 \\
$n=58-131$ & 229 & 4.8 & 0.36 & 8.6 & 2.2 \\
$n=58-132$ & 226 & 6.0 & 0.45 & 8.5 & 2.2 \\
$n=69-133$ & 182 & 4.4 & 0.32 & 6.6 & 2.1 \\
$n=37-90$ & 181 & 4.2 & 0.32 & 7.0 & 2.6 \\
$n=61-130$ & 172 & 4.0 & 0.32 & 6.9 & 3.1 \\
$n=53-127$ & 130 & 6.1 & 0.60 & 6.5 & 2.2 \\
\hline
\end{tabular}

constants increase with temperature, while the Langevin rate ${ }^{63}$ for collisions of non-polar molecules with a point charge as part of average dipole orientation (ADO) theory ${ }^{64}$ is independent from temperature, illustrated in Fig. 3. Also the efficiency $\Phi_{\mathrm{ADO}}=k_{\mathrm{abs}} / k_{\mathrm{ADO}}$ is unrealistically high, reaching $150 \%$ at room temperature. Since it cannot be expected that water clusters with up to 130 molecules behave like a point charge, we employed two

a)

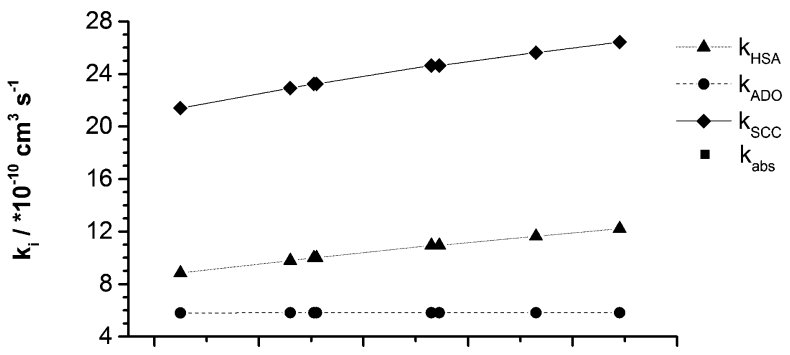

b)

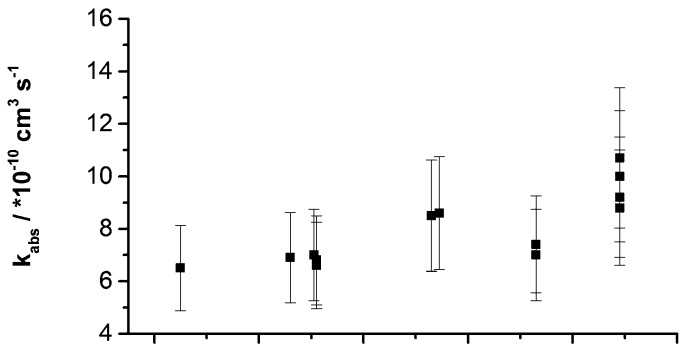

c)

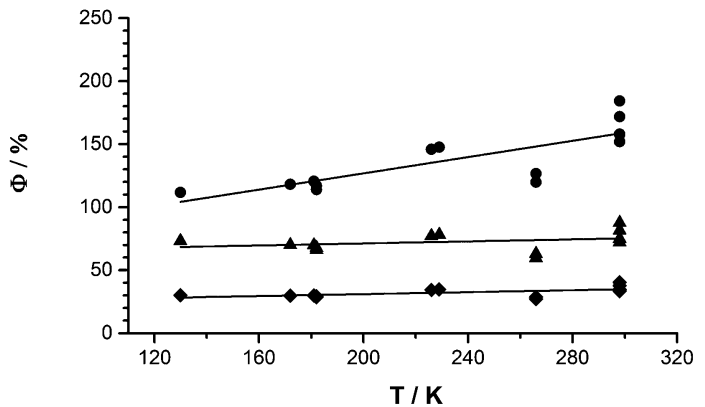

Fig. 3 (a) Calculated collision rates with three different models. (b) Experimental rate constants. (c) Efficiencies $\Phi_{\mathrm{HSA}}=k_{\mathrm{abs}} / k_{\mathrm{HSA}}$ (triangle), $\Phi_{\mathrm{ADO}}=k_{\mathrm{abs}} / k_{\mathrm{ADO}}$ (circle) and $\Phi_{\mathrm{SCC}}=k_{\mathrm{abs}} / k_{\mathrm{SCC}}$ (diamonds). 
collision models that account for the finite size of the clusters, the hard-sphere ADO model (HSA) and the surface-charge capture (SCC) model. ${ }^{65}$ Both models reproduce the temperature dependence of the experimental data, and result in temperature-independent collision efficiencies of $\Phi_{\mathrm{HSA}}=70 \%$ and $\Phi_{\mathrm{SCC}}=30 \%$, respectively. The actual collision efficiency lies somewhere in between. The origin of the temperature dependence lies in the finite size of water cluster. In the Langevin model, the rate increasing effect of the higher velocity exactly cancels out with the rate decreasing effect of a smaller impact parameter for ion-induced dipole capture. With the contribution of the geometric cross section in the HSA and SCC models, the velocity of the neutral collision partner becomes more important, resulting in more frequent collisions with increasing temperature.

The nanocalorimetry results range from $\Delta N_{\text {vap }}=2.1$ to 3.4 evaporated water molecules, Table 1 . A simultaneous fit of all data sets yields $\Delta N_{\text {vap,sim }}(3)=2.4$ water molecules. Taking the average of all measured data sets, we obtain $\Delta N_{\text {vap }}(3)=2.46 \pm$ 0.75 , where twice the standard deviation is taken as a conservative estimate for the error. This translates into $\Delta E_{\text {raw }}(3)=-107 \pm$ $39 \mathrm{~kJ} \mathrm{~mol}^{-1}$. Thermal corrections as outlined previously ${ }^{24}$ are small, we can convert this nanocalorimetry result to $\Delta H_{298 \mathrm{~K}}(3)=$ $-105 \pm 39 \mathrm{~kJ} \mathrm{~mol}^{-1}$. Details of the conversion are given in the ESI. $\dagger$

A similar series of experiments was performed for the uptake of molecular oxygen by hydrated electrons, reaction (4).

$$
\left(\mathrm{H}_{2} \mathrm{O}\right)_{n}^{\bullet-}+\mathrm{O}_{2} \rightarrow \mathrm{O}_{2}^{\bullet-}\left(\mathrm{H}_{2} \mathrm{O}\right)_{n-m}+m \mathrm{H}_{2} \mathrm{O}
$$

Mass spectra are shown in Fig. S1 (ESI $\dagger$ ), kinetics and nanocalorimetry in Fig. S2 (ESI $\dagger$ ). Similar to $\mathrm{CO}_{2}$, we observe an overall increase in the reaction rate with temperature, from $1.1 \times 10^{-10} \mathrm{~cm}^{3} \mathrm{~s}^{-1}$ to $1.5 \times 10^{-10} \mathrm{~cm}^{3} \mathrm{~s}^{-1}$, Table 2 . With the SCC model, Fig. S3 (ESI $\dagger$ ), the collision efficiency is independent of temperature, $\Phi_{\mathrm{SCC}}=5.6 \%$. The HSA model results in a negative temperature dependence, with efficiencies of $\Phi_{\mathrm{HSA}}=$ $14 \%$ at $T=80 \mathrm{~K}$ down to $\Phi_{\mathrm{HSA}}=11 \%$ at $300 \mathrm{~K}$. The Langevin collision rate results in a positive temperature dependence of the collision efficiency.

Nanocalorimetry yields values $\Delta N_{\text {vap }}=6.0$ to 6.6 , Table 2 . A simultaneous fit of all data sets yields $\Delta N_{\text {vap,sim }}(4)=6.4$

Table 2 Initial cluster size range, temperature, reactant gas pressure, relative and absolute rate constants $k_{\text {rel }}$ and $k_{\text {abs }}$, respectively, and average number of evaporated water molecules $\Delta \mathrm{N}_{\text {vap }}$ for the reaction of $\left(\mathrm{H}_{2} \mathrm{O}\right)_{n}{ }^{\bullet-}$ with $\mathrm{O}_{2}$

\begin{tabular}{llllll}
\hline $\mathrm{O}_{2}+\left(\mathrm{H}_{2} \mathrm{O}\right)_{n}^{\bullet-}$ & $T / \mathrm{K}$ & $p_{\mathrm{m}} / 10^{-9} \mathrm{mbar}$ & $k_{\mathrm{rel}} / \mathrm{s}^{-1}$ & $k_{\mathrm{abs}} / 10^{-10} \mathrm{~cm}^{3} \mathrm{~s}^{-1}$ & $\Delta N_{\text {vap }}$ \\
\hline$n=59-132$ & 298 & 5.5 & 0.078 & 1.4 & 6.1 \\
$n=56-133$ & 298 & 6.0 & 0.098 & 1.6 & 6.5 \\
$n=44-96$ & 298 & 5.5 & 0.076 & 1.3 & 6.4 \\
$n=36-82$ & 298 & 6.1 & 0.090 & 1.4 & 5.5 \\
$n=70-126$ & 237 & 5.7 & 0.11 & 1.4 & 6.6 \\
$n=59-123$ & 176 & 7.4 & 0.19 & 1.5 & 6.6 \\
$n=52-124$ & 172 & 7.9 & 0.21 & 1.5 & 6.6 \\
$n=52-125$ & 171 & 7.7 & 0.21 & 1.5 & 6.6 \\
$n=64-125$ & 140 & 8.0 & 0.24 & 1.4 & 6.6 \\
$n=66-128$ & 136 & 5.2 & 0.12 & 1.0 & 6.1 \\
$n=67-129$ & 95 & 5.5 & 0.21 & 1.2 & 6.0 \\
$n=69-131$ & 86 & 8.0 & 0.31 & 1.1 & 6.3
\end{tabular}

Table 3 Initial cluster size range, temperature, reactant gas pressure, relative and absolute rate constants $k_{\text {rel }}$ and $k_{\text {abs }}$, respectively, and average number of evaporated water molecules $\Delta N_{\text {vap }}$ for the reaction of $\mathrm{CO}_{2}{ }^{-}-\left(\mathrm{H}_{2} \mathrm{O}\right)_{n}$ with $\mathrm{O}_{2}$

\begin{tabular}{|c|c|c|c|c|c|}
\hline $\mathrm{O}_{2}+\mathrm{CO}_{2}^{\bullet-}\left(\mathrm{H}_{2} \mathrm{O}\right)_{n}$ & $T / \mathrm{K}$ & $p_{\mathrm{m}} / 10^{-9} \mathrm{mbar}$ & $k_{\text {rel }} / \mathrm{s}^{-1}$ & $k_{\mathrm{abs}} / 10^{-10} \mathrm{~cm}^{3} \mathrm{~s}^{-1}$ & $\Delta N_{\text {vap }}$ \\
\hline$n=53-115$ & 298 & 61 & 0.24 & 0.37 & 3.0 \\
\hline$n=51-114$ & 298 & 9.4 & 0.041 & 0.42 & 3.3 \\
\hline$n=61-121$ & 298 & 8.5 & 0.22 & 0.35 & 3.9 \\
\hline$n=53-115$ & 231 & 8.6 & 0.056 & 0.49 & 3.2 \\
\hline$n=51-117$ & 232 & 10 & 0.066 & 0.49 & 2.8 \\
\hline$n=61-121$ & 167 & 8.5 & 0.073 & 0.47 & 3.7 \\
\hline$n=60-129$ & 120 & 9.5 & 0.10 & 0.41 & 3.6 \\
\hline$n=58-121$ & 107 & 9.9 & 0.12 & 0.41 & 3.4 \\
\hline$n=49-108$ & 85 & 9.9 & 0.13 & 0.36 & 3.6 \\
\hline$n=53-106$ & 84 & 9.9 & 0.13 & 0.37 & 3.5 \\
\hline
\end{tabular}

evaporated water molecules, identical to the average of all measured values $\Delta N_{\text {vap }}(4)=6.40 \pm 0.45$, which corresponds to $\Delta E_{\text {raw }}(4)=-277 \pm 28 \mathrm{~kJ} \mathrm{~mol}^{-1}$ and $\Delta H_{298 \mathrm{~K}}(4)=-276 \pm 28 \mathrm{~kJ} \mathrm{~mol}^{-1}$.

At last the core exchange reaction of $\mathrm{CO}_{2}{ }^{\bullet-}\left(\mathrm{H}_{2} \mathrm{O}\right)_{n}$ with $\mathrm{O}_{2}$ is analyzed, reaction (5), with mass spectra and kinetic as well as nanocalorimetric fits shown in Fig. S4 and S5 (ESI $\dagger$ ), respectively.

$$
\mathrm{CO}_{2}^{\bullet-}\left(\mathrm{H}_{2} \mathrm{O}\right)_{n}+\mathrm{O}_{2} \rightarrow \mathrm{O}_{2}^{\bullet-}\left(\mathrm{H}_{2} \mathrm{O}\right)_{n-m}+\mathrm{CO}_{2}+m \mathrm{H}_{2} \mathrm{O}
$$

The kinetic analysis yields reaction rates $k_{\mathrm{abs}}(5)=3.5-4.9 \times$ $10^{-11}$ mbar, Table 3 and Fig. S6 (ESI $\dagger$ ). Interestingly, the highest rate is observed for temperatures around $230 \mathrm{~K}$. A maximum in the rate is a result of a pronounced negative temperature dependence of the collision efficiency, multiplied with the collision rate exhibiting positive temperature dependence, Fig. S6 (ESI $\dagger$ ). At room temperature, the efficiencies are $\Phi_{\mathrm{HSA}}=2.8 \%$ and $\Phi_{\mathrm{SCC}}=1.4 \%$.

Nanocalorimetry of individual data sets yields $\Delta N_{\text {vap }}=2.8$ to 3.9 evaporated water molecules, Table 3 . The simultaneous fit of all data sets results in $\Delta N_{\text {vap,sim }}(5)=3.4$ evaporated water molecules, again identical to the average value of individual data sets $\Delta N_{\text {vap }}(5)=3.40 \pm 0.63$, which corresponds to $\Delta E_{\text {raw }}(5)=$ $-147 \pm 29 \mathrm{~kJ} \mathrm{~mol}^{-1}$ and $\Delta H_{298 \mathrm{~K}}(5)=-146 \pm 29 \mathrm{~kJ} \mathrm{~mol}^{-1}$.

As described by Lee and Castleman, ${ }^{66}$ stepwise hydration energies of ions become independent from the ion already with a few water molecules. Extrapolating this idea to the bulk, this means we can identify the values $\Delta H_{298 \mathrm{~K}}(3-5)$ with the enthalpy of the corresponding reaction in bulk aqueous solution at room temperature. In this way, we can derive the hydration enthalpies of the radical anions $\mathrm{CO}_{2}{ }^{\bullet-}$ and $\mathrm{O}_{2}{ }^{\bullet-}$ applying Hess' law, Tables 4 and 5 , respectively. This yields $\Delta_{\text {hyd }} H\left(\mathrm{CO}_{2}{ }^{--}\right)=-334 \pm$ $44 \mathrm{~kJ} \mathrm{~mol}^{-1}$ and $\Delta_{\mathrm{hyd}} H\left(\mathrm{O}_{2}{ }^{--}\right)=-404 \pm 28 \mathrm{~kJ} \mathrm{~mol}^{-1}$.

\section{Discussion of experimental results}

Rates. The measured rates and their temperature dependence reveal interesting aspects of the reaction dynamics. ${ }^{67}$ The rate of the $\mathrm{CO}_{2}$ uptake by hydrated electron, reaction (3), agrees within error limits with previously published values for other cluster sizes, Table 6 . The high efficiency around 50\% indicates a mechanistically simple reaction, in which $\mathrm{CO}_{2}$ recombines with the hydrated electron. This requires some rearrangement of 
Table 4 Thermochemical cycle for $\left.\Delta_{\text {hyd }} H_{\left(\mathrm{CO}_{2}\right.}{ }^{-}\right)^{a}$

\begin{tabular}{lcl}
\hline Reaction & $\Delta H_{298 \mathrm{~K}} / \mathrm{kJ} \mathrm{mol}^{-1}$ & Ref. \\
\hline $\mathrm{CO}_{2}^{\bullet-}(\mathrm{g}) \rightarrow \mathrm{CO}_{2}(\mathrm{~g})+\mathrm{e}^{-}(\mathrm{g})$ & $-58 \pm 19$ & 72 and 73 \\
$\mathrm{e}^{-}(\mathrm{g}) \rightarrow \mathrm{e}^{-}(\mathrm{aq})$ & $-170.7 \pm 3.8^{a}$ & 74 \\
$\mathrm{CO}_{2}(\mathrm{~g})+\mathrm{e}^{-}(\mathrm{aq}) \rightarrow \mathrm{CO}_{2}^{\bullet-}(\mathrm{aq})$ & $-105 \pm 39$ & This work \\
$\mathrm{CO}_{2}^{\bullet-}(\mathrm{g}) \rightarrow \mathrm{CO}_{2}^{\bullet-}(\mathrm{aq})$ & $-334 \pm 44$ & Sum of above \\
${ }^{a}$ Referenced to $\Delta_{\mathrm{hyd}} H\left(\mathrm{H}^{+}\right)=-1090 \mathrm{~kJ} \mathrm{~mol}^{-1}$. & \\
\hline
\end{tabular}

Table 5 Thermochemical cycle for $\left.\Delta_{\text {hyd }} H_{\left(\mathrm{O}_{2}\right.}{ }^{--}\right)^{a}$

\begin{tabular}{lcl}
\hline Reaction & $\Delta H_{298 \mathrm{~K}} / \mathrm{kJ} \mathrm{mol}^{-1}$ & Ref. \\
\hline $\mathrm{O}_{2}{ }^{\bullet-}(\mathrm{g}) \rightarrow \mathrm{O}_{2}(\mathrm{~g})+\mathrm{e}^{-}(\mathrm{g})$ & $43 \pm 1$ & 75 \\
$\mathrm{e}^{-}(\mathrm{g}) \rightarrow \mathrm{e}^{-}(\mathrm{aq})$ & $-170.7 \pm 3.8^{a}$ & 74 \\
$\mathrm{O}_{2}(\mathrm{~g})+\mathrm{e}^{-}(\mathrm{aq}) \rightarrow \mathrm{O}_{2}{ }^{--}(\mathrm{aq})$ & $-276 \pm 28$ & This work \\
$\mathrm{O}_{2}{ }^{-}(\mathrm{g}) \rightarrow \mathrm{O}_{2}{ }^{\bullet-}(\mathrm{aq})$ & $-404 \pm 28$ & Sum of above \\
${ }^{a}$ Referenced to $\Delta_{\mathrm{hyd}} H\left(\mathrm{H}^{+}\right)=-1090 \mathrm{~kJ} \mathrm{~mol}^{-1}$. & \\
\hline
\end{tabular}

hydrogen bonds, in which the individual steps face barriers around $20 \mathrm{~kJ} \mathrm{~mol}^{-1}$, the energy of a hydrogen bond. The reaction also does not face any spin restrictions.

The situation is different for $\mathrm{O}_{2}$, which, as outlined before, ${ }^{22}$ faces spin restrictions. The triplet ground state of $\mathrm{O}_{2}$ and the doublet of the hydrated electron form an energetically accessible doublet and an inaccessible quartet product state. The statistical weight of the accessible doublet state is $1 / 3$. The observed rate, however, is significantly lower than one third of the collision rate, and lower than previously reported, see Table 6 . The deviation from our own previous work is probably due to a malfunction of the pressure gauge in the previously published experiment. $^{24}$ The deviation of $40 \%$ from the results of Arnold et $a .^{22}$ are almost within the error limits of the pressure calibration. However, the different cluster sizes used may also contribute. It is conceivable that in the relatively large clusters used in the present study, the $\mathrm{O}_{2}$ molecule has a smaller chance of colliding with the cluster in the right place to interact with the localized hydrated electron. Without mass selection, however, this remains speculative.

The even lower rate of the exchange reaction (5) together with the clearly negative temperature dependence is very intriguing. Here, the agreement with our earlier study is very good, probably because the exchange reaction in the earlier study was measured after maintenance work on the ion gauge. This reaction faces the same spin restrictions as the reaction of $\mathrm{O}_{2}$ with hydrated electrons, yet it is a factor of four slower, with efficiencies of only $2-3 \%$ at room temperature. This suggests that the initial step of the reaction is formation of a hydrated $\mathrm{CO}_{4}{ }^{\bullet-}$ complex. Since $\mathrm{O}_{2}$ does not interact strongly with neutral water molecules, it rapidly evaporates if it collides with the water cluster remotely from $\mathrm{CO}_{2}{ }^{\bullet-}$. The low rate of reaction (5) is most likely a steric effect in the formation of the $\mathrm{CO}_{4}{ }^{\bullet-}$ intermediate.

Thermochemistry. The nanocalorimetry results for reactions (3) and (4) both lie 0.5-0.6 water molecules below the estimates by Posey et al., ${ }^{21}$ see Table 6, and 1.2-1.4 water molecules above the results by Arnold et al. ${ }^{22}$ They are also 0.6-1.5 molecules higher than our previous results, ${ }^{24}$ which were derived from only one data set. Only for reaction (5) our previous result agrees with the present one within error limits. For all three reactions, the nanocalorimetry results lie in the range obtained from visual inspection of the mass spectra by Balaj et al. ${ }^{23}$ Given that the results from the present study are each the average of more than 10 independent measurements, and at the same time they lie in the range spanned by four independent studies from three different groups, we are confident that the present results are valid within their very conservative error limits.

Reactions (3)-(5) are connected with a thermochemical cycle, eqn (6). Comparing the two sides of the equation, we get agreement within error limits, eqn (7) and (8). This self-consistency of the results, which is reached in the present study, is another positive test for the validity of the results and the method.

$$
\Delta_{\mathrm{r}} H(3)+\Delta_{\mathrm{r}} H(5)=\Delta_{\mathrm{r}} H(4)
$$

Table 6 Comparison of reaction rates $k_{\text {abs, }}$ number of evaporated water molecules $\Delta N_{\text {vap }}$, reaction enthalpy $\Delta H_{R}$ and hydration enthalpy of radical anions $\Delta H_{\text {hyd }}$ from five different studies

\begin{tabular}{|c|c|c|c|c|c|}
\hline Reaction & Source & $k_{\mathrm{abs}} / \mathrm{cm}^{3} \mathrm{~s}^{-1}$ at $298 \mathrm{~K}$ & $\Delta N_{\text {vap }}$ & $\Delta_{\mathrm{r}} H / \mathrm{kJ} \mathrm{mol}^{-1}$ & $\Delta_{\text {hyd }} H / \mathrm{kJ} \mathrm{mol}^{-1}$ \\
\hline (3) $\mathrm{CO}_{2}+\left(\mathrm{H}_{2} \mathrm{O}\right)_{n}^{\bullet-}$ & $\begin{array}{l}\text { This work } \\
\text { Höckendorf et al. } \\
\text { Arnold } \text { et al. }{ }^{c} \\
\text { Posey et al. }{ }^{d} \\
\text { Balaj et al. }{ }^{g}\end{array}$ & $\begin{array}{l}9.8 \times 10^{-10} \\
1.0 \times 10^{-9} \\
7.6 \times 10^{-10} \\
-\end{array}$ & $\begin{array}{l}2.46 \pm 0.75 \\
1.0 \pm 0.2 \\
1.3 \\
3 \\
2-3\end{array}$ & $\begin{array}{l}-105 \pm 39 \\
-39 \pm 9 \\
-105.2^{e}\end{array}$ & $\begin{array}{l}-334 \pm 44^{a} \\
-268 \pm 27 \\
-333.8^{f}\end{array}$ \\
\hline (4) $\mathrm{O}_{2}+\left(\mathrm{H}_{2} \mathrm{O}\right)_{n}^{\bullet-}$ & $\begin{array}{l}\text { This work } \\
\text { Höckendorf et al. } \\
\text { Arnold et al. } \\
\text { Posey et al. } \\
\text { Balaj et al. }\end{array}$ & $\begin{array}{l}1.4 \times 10^{-10} \\
5.4 \times 10^{-10} \\
2.5 \times 10^{-10} \\
-\end{array}$ & $\begin{array}{l}6.40 \pm 0.45 \\
5.8 \pm 0.2 \\
5.0 \\
7 \\
5-6\end{array}$ & $\begin{array}{l}-276 \pm 28 \\
-247 \pm 20 \\
-317^{e}\end{array}$ & $\begin{array}{l}-404 \pm 28^{a} \\
-375 \pm 30 \\
-445.8^{f}\end{array}$ \\
\hline (5) $\mathrm{O}_{2}+\mathrm{CO}_{2} \cdot-\left(\mathrm{H}_{2} \mathrm{O}\right)_{n}$ & $\begin{array}{l}\text { This work } \\
\text { Höckendorf et al. } \\
\text { Balaj et al. }\end{array}$ & $\begin{array}{l}3.7 \times 10^{-11} \\
4.1 \times 10^{-11}\end{array}$ & $\begin{array}{l}3.40 \pm 0.63 \\
3.5 \pm 0.2 \\
3-4\end{array}$ & $\begin{array}{l}-146 \pm 29 \\
-149 \pm 14\end{array}$ & \\
\hline
\end{tabular}

${ }^{a}$ Referenced to $\Delta_{\text {hyd }} H\left(\mathrm{H}^{+}\right)=-1090 \mathrm{~kJ} \mathrm{~mol}^{-1} \cdot{ }^{b}$ Ref. $24 .{ }^{c}$ Ref. $22 .{ }^{d}$ Ref. $21 .{ }^{e}$ Estimated reaction enthalpy from ref. 21 combined with the electron hydration enthalpy from ref. 74 , referenced to $\Delta_{\text {hyd }} H\left(\mathrm{H}^{+}\right)=-1090 \mathrm{~kJ} \mathrm{~mol}{ }^{-1} \cdot{ }^{f}$ Estimated by Posey et al., ref. 21 , based on data from ref. 76 and 66 . ${ }^{g}$ Ref. 23. 


$$
\begin{gathered}
\Delta_{\mathrm{r}} H(3)+\Delta_{\mathrm{r}} H(5)=-105 \pm 39-146 \pm 29 \mathrm{~kJ} \mathrm{~mol}^{-1} \\
=-251 \pm 49 \mathrm{~kJ} \mathrm{~mol}^{-1} \\
\Delta_{\mathrm{r}} H(4)=-276 \pm 28
\end{gathered}
$$

In our previous study, eqn (6) was not fulfilled, which led us to the conclusion that the exchange reaction of $\mathrm{CO}_{2}{ }^{--}\left(\mathrm{H}_{2} \mathrm{O}\right)_{n}$ with $\mathrm{O}_{2}$, reaction (5), had a significant non-ergodic component. We suggested that the $\mathrm{CO}_{2}$ product was vibrationally excited. The present, more reliable results do no longer support this interpretation. Since (7) and (8) agree within error limits, the results are completely consistent with a fully ergodic reaction (5). The ergodicity assumption (C) seems to be valid. No dependence on temperature or initial cluster size distribution is apparent from the results, Tables 1-3, suggesting that also assumptions (A) and (B) are valid.

Hydration enthalpies. The new hydration enthalpies lie in the range of the values estimated by Posey et $a{ }^{21}$ from a combination of literature thermochemistry. The hydration enthalpy of $\mathrm{CO}_{2}{ }^{--}$is in excellent agreement, while the value for $\mathrm{O}_{2}^{\bullet-}$ is $40 \mathrm{~kJ} \mathrm{~mol}^{-1}$ lower than the literature estimate.

\section{Mechanism of the exchange reaction between $\mathrm{CO}_{2}{ }^{\bullet-}\left(\mathrm{H}_{2} \mathrm{O}\right)_{n}$ and $\mathrm{O}_{2}$}

The low rate of the exchange reaction (5) and its negative temperature dependence indicate that the reaction proceeds via the formation of $\mathrm{a} \mathrm{CO}_{4}{ }^{--}$intermediate. To learn more about the mechanism, we performed quantum chemical calculations on the reaction path of reaction (5) for $n=5$ and 10 using DFT at the unrestricted M06-2X/6-311++G(d,p) level of theory.

For $n=5$, as shown in Fig. 4, the reaction begins with an interaction between the doublet $\mathrm{CO}_{2}{ }^{\bullet-}$ and the triplet $\mathrm{O}_{2}$ and forms an intermediate complex $\mathbf{i 5 I}(\mathbf{q})$ with a binding energy of $10 \mathrm{~kJ} \mathrm{~mol}^{-1}$. A single-point calculation on the geometry of i5I(q) at doublet spin state predicted $\mathbf{i 5 I}(\mathbf{d})$ in which the spin of $\mathrm{CO}_{2}{ }^{\bullet-}$ is anti-parallel with that of $\mathrm{O}_{2}$. The relative energy of i5I(d) $\left(-11 \mathrm{~kJ} \mathrm{~mol}^{-1}\right.$, including zero-point energy correction obtained from a harmonic vibration analysis giving one imaginary frequency) is almost iso-energetic with $\mathbf{i 5 I}(\mathbf{q})$. It should be noted that for technical reasons, the geometry of the intermediate complex i5I can only be optimized on the quartet surface, while the reaction may start on either the quartet or the doublet surface, depending on the orientation of the $\mathrm{CO}_{2}{ }^{\bullet-}$ spin relative to the spin of $\mathrm{O}_{2}$. It is quite reasonable to expect that the anti-parallel spin state can readily result, without any barrier, in a radical recombination reaction to yield $\mathrm{CO}_{4}{ }^{\bullet-}\left(\mathrm{H}_{2} \mathrm{O}\right)_{5}$ (i5II) with a relative energy of $-178 \mathrm{~kJ} \mathrm{~mol}^{-1}$. If all spins are parallel, the radical recombination in i5I is also predicted to be facile via a transition state with a relative energy of around $6 \mathrm{~kJ} \mathrm{~mol}^{-1}$, estimated roughly from the crossing between the quartet and doublet surfaces of $\mathrm{CO}_{4}{ }^{\bullet-}\left(\mathrm{H}_{2} \mathrm{O}\right)_{5}$ with respect to the distance of the forming $\mathrm{C}-\mathrm{O}$ bond (Fig. S7, ESI $\dagger$ ). These results support that $\mathrm{CO}_{4}{ }^{--}$is an intermediate for the exchange reaction between $\mathrm{CO}_{2}{ }^{--}$and $\mathrm{O}_{2}$ and the spin restriction of the initial radical recombination is not likely a limiting factor. The distance of the newly formed $\mathrm{C}-\mathrm{O}$ bond in $\mathbf{1 5 I I}$ is $1.527 \AA$ A. This reaction slightly alters the OCO angle of the $\mathrm{CO}_{2}$ from $135^{\circ}$ to $137^{\circ}$. In $\mathrm{CO}_{4}{ }^{\circ-}$, the spin is mainly located at a $\pi^{*}$-orbital of the ${ }^{\bullet} \mathrm{OO}-$ moiety leaving the anionic charge mainly on the two oxygen atoms of the $-\mathrm{CO}_{2}{ }^{-}$ moiety, which is then stabilized by solvation. A subsequent heterolytic cleavage of the $\mathrm{C}-\mathrm{O}$ bond of $\mathrm{CO}_{4}{ }^{--}$can occur via a transition structure (i5ts), with a relative energy of $-143 \mathrm{~kJ} \mathrm{~mol}^{-1}$ and the $\mathrm{C}-\mathrm{O}$ distance and OCO angle being $2.190 \AA$ and $164^{\circ}$, resulting in $\mathrm{O}_{2}{ }^{--}$and $\mathrm{CO}_{2}$ in i5IV or i5V. Eliminating $\mathrm{CO}_{2}$ from the intermediates gives the final product $\mathrm{O}_{2}^{\bullet-}\left(\mathrm{H}_{2} \mathrm{O}\right)_{5}(\mathrm{p} 5)+\mathrm{CO}_{2}$. The overall exchange reaction is exothermic by $138 \mathrm{~kJ} \mathrm{~mol}^{-1}$.

Similar DFT analysis was also performed for the radical recombination between $\mathrm{CO}_{2}{ }^{\bullet-}\left(\mathrm{H}_{2} \mathrm{O}\right)_{10}$ and $\mathrm{O}_{2}$. The reaction energies and some selected geometries are summarized in

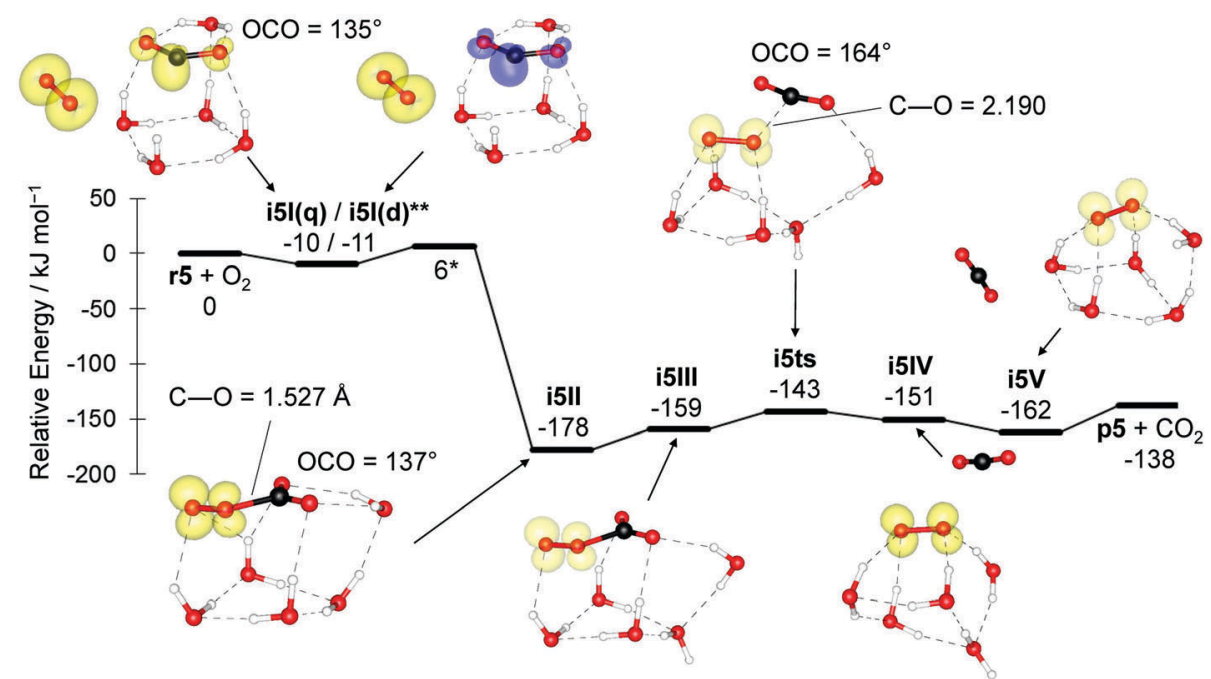

Fig. 4 Potential energy profile for the exchange reaction $\mathrm{CO}_{2}{ }^{-}-\left(\mathrm{H}_{2} \mathrm{O}\right)_{5}+\mathrm{O}_{2} \rightarrow \mathrm{O}_{2}{ }^{-}-\left(\mathrm{H}_{2} \mathrm{O}\right)_{5}+\mathrm{CO}_{2}$. The relative energies, in $\mathrm{kJ}$ mol ${ }^{-1}$, were evaluated at M06-2X/6-311++G(d,p) level of theory. *The transition state for the radical recombination between $\mathrm{CO}_{2}{ }^{\cdot-}$ and $\mathrm{O}_{2}$ was estimated roughly by the crossing between the quartet and doublet surface of $\mathrm{CO}_{4}{ }^{--}$with respect to the $\mathrm{C}-\mathrm{O}$ distance. ${ }^{* *}$ The doublet i5I(d) was obtained from a single-point calculation on the geometry of the quintet i5I(q). The spin densities were plotted with iso-values of 0.02 (yellow) and -0.02 (blue). 
Table 7 Relative energies, in $\mathrm{kJ} \mathrm{mol}^{-1}$, for the exchange reaction $\mathrm{CO}_{2}{ }^{-}{ }^{-}\left(\mathrm{H}_{2} \mathrm{O}\right)_{10}+\mathrm{O}_{2} \rightarrow \mathrm{O}_{2}{ }^{-}\left(\mathrm{H}_{2} \mathrm{O}\right)_{10}+\mathrm{CO}_{2}$. The relative energies, in $\mathrm{kJ} \mathrm{mol}^{-1}$, were evaluated at M06-2X/6-311++G(d,p) level of theory. The geometries are shown in Fig. 5 and Fig. S8 (ESI)

\begin{tabular}{lrrr}
\hline $\mathbf{x}=\mathbf{a}, \mathbf{b}$ or $\mathbf{c}$ & $\mathbf{a}$ & $\mathbf{b}$ & \multicolumn{1}{c}{$\mathbf{c}$} \\
\hline $\mathbf{r 1 0}-\mathbf{x}+\mathrm{O}_{2}$ & 0 & 6 & 9 \\
i10I-x & -10 & -3 & -1 \\
i10II-x & -170 & -164 & -158 \\
i10ts-x & -127 & -130 & -138 \\
i10III-x & -130 & -138 & -149 \\
i10IV-x & -166 & -169 & -160 \\
p10-x $+\mathrm{CO}_{2}$ & -142 & -145 & -140 \\
\hline
\end{tabular}

Table 7 and Fig. 5 (and Fig. S8, ESI $\dagger$ ), respectively. Three structures for the reactant $\mathrm{CO}_{2}{ }^{\bullet-}\left(\mathrm{H}_{2} \mathrm{O}\right)_{10}(\mathbf{r 1 0}-\mathbf{x}$, where $\mathrm{x}=\mathrm{a}$, $\mathrm{b}$ and $\mathrm{c}$ ) were considered. They were analogs of the low-energy fused cubic structure of the neutral water cluster $\left(\mathrm{H}_{2} \mathrm{O}\right)_{12},{ }^{68-70}$ from which two adjacent water molecules were replaced by $\mathrm{CO}_{2}{ }^{-}$. In general, the fused cubic structures are lower in energy than the less-ordered liquid-like structures (Table S1, ESI $\dagger$ ). As the smaller size of $n=5, \mathrm{O}_{2}$ can form a weakly bound complex with $\mathrm{CO}_{2}{ }^{\bullet-}\left(\mathrm{H}_{2} \mathrm{O}\right)_{10}(\mathbf{i 1 0 I - x}(\mathbf{q})$ in Fig. S8, ESI $\dagger)$ also with binding energies of around $10 \mathrm{~kJ} \mathrm{~mol}^{-1}$. With appropriate spin orientation, that is the spin of $\mathrm{CO}_{2}{ }^{\bullet-}$ is anti-parallel to that of $\mathrm{O}_{2}$ (i10I-x(d) in Fig. S8, ESI $\dagger$ ), $\mathrm{CO}_{4}{ }^{-}-\left(\mathrm{H}_{2} \mathrm{O}\right)_{10}$ can also be formed with $\mathrm{C}-\mathrm{O}$ bond lengths of 1.51 (i10II-a), 1.52 (i10II-b) and $1.48 \AA$ (i10II-c) as shown in Fig. 5. Their relative energies are similar with values ranging in -170 to $-158 \mathrm{~kJ} \mathrm{~mol}^{-1}$. The transition structures associated with the heterolytic $\mathrm{C}-\mathrm{O}$ bond cleavage of $\mathrm{CO}_{4}{ }^{\bullet-}$ for the studied geometries are $-127 \mathrm{~kJ} \mathrm{~mol}^{-1}$ (i10ts-a), $-130 \mathrm{~kJ} \mathrm{~mol}^{-1}$ (i10ts-b) and $-138 \mathrm{~kJ} \mathrm{~mol}^{-1}$ (i10ts-c). It is interesting to note that the descending energy order of these transition structures (i10ts-a $>$ i10ts-b $>$ i10ts-c) are negatively correlated with the extents of the heterolytic bond cleavage with the $\mathrm{C}-\mathrm{O}$ distance and OCO angle increasing from $2.06 \AA$ and $159^{\circ}$ (i10ts-c) to $2.09 \AA$ and $164^{\circ}$ (i10ts-b) then to $2.35 \AA$ and $169^{\circ}$ (i10ts-a). The structure of i10ts-c has lower energy probably because the resulting $\mathrm{O}_{2}{ }^{--}$is internally solvated and thus better stabilized by hydrogen bonds, hence favoring the charge exchange reaction via the heterolytic $\mathrm{C}-\mathrm{O}$ bond cleavage of the $\mathrm{CO}_{4}{ }^{\bullet-}$ intermediate. The exchanged $\mathrm{O}_{2}{ }^{\bullet-}$ products are then further stabilized upon solvent reorganization from i10III-x $\left(-149\right.$ to $\left.-130 \mathrm{~kJ} \mathrm{~mol}^{-1}\right)$ to i10IV-x $\left(-169\right.$ to $\left.-160 \mathrm{~kJ} \mathrm{~mol}^{-1}\right)$. Eliminating $\mathrm{CO}_{2}$ results in p10-x. The overall reaction energies for $n=10$ are exothermic by $140-145 \mathrm{~kJ} \mathrm{~mol}^{-1}$, which are close to the value for $n=5$ of $138 \mathrm{~kJ} \mathrm{~mol}^{-1}$. The theoretical reaction energies are independent of cluster size and are also in excellent agreement with the nanocalorimetric value of $-147 \pm 29 \mathrm{~kJ} \mathrm{~mol}^{-1}$.

\section{Molecular dynamics simulations for the exchange reaction between $\mathrm{CO}_{2}{ }^{\bullet-}\left(\mathrm{H}_{2} \mathrm{O}\right)_{10}$ and $\mathrm{O}_{2}$}

The reaction dynamics between $\mathrm{CO}_{2}^{\bullet-}\left(\mathrm{H}_{2} \mathrm{O}\right)_{n}$ and $\mathrm{O}_{2}$ is further examined by DFT-MD simulations with a cluster of size $n=10$. A MD trajectory (5 ps) for a quartet $\left[\mathrm{O}_{2}, \mathrm{CO}_{2}{ }^{--}\left(\mathrm{H}_{2} \mathrm{O}\right)_{n}\right]$ complex (an analog of i10I-a(q)) with $\mathrm{O}_{2}$ being close to $\mathrm{CO}_{2}{ }^{\bullet-}$ (by ca. 3-4 $\AA$ ) was firstly obtained at a temperature of $100 \mathrm{~K}$ under the NVT condition.
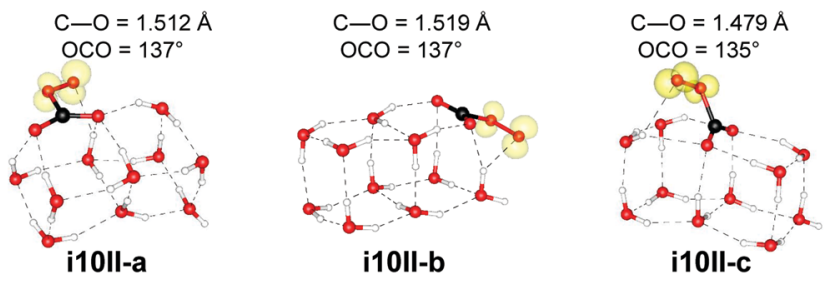

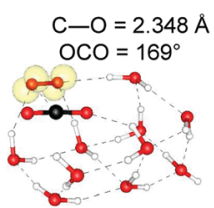

i10ts-a

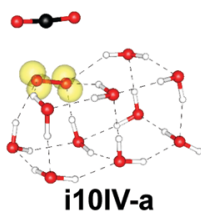

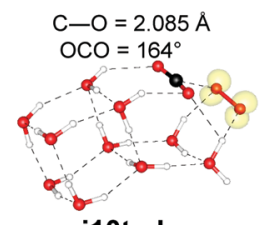

i10ts-b

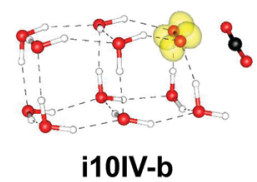

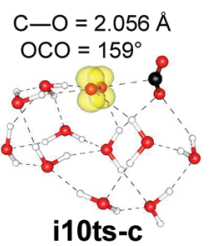

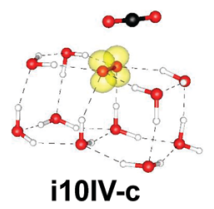

Fig. 5 Some selected geometries for the exchange reaction $\mathrm{CO}_{2}{ }^{-}-\left(\mathrm{H}_{2} \mathrm{O}\right)_{10}+$ $\mathrm{O}_{2} \rightarrow \mathrm{O}_{2}{ }^{-}-\left(\mathrm{H}_{2} \mathrm{O}\right)_{10}+\mathrm{CO}_{2}$. The spin densities were plotted with iso-values of 0.02 (yellow surfaces).

As expected, $\mathrm{O}_{2}$ was weakly bound on the cluster surface without reacting with $\mathrm{CO}_{2}{ }^{\bullet-}$ at the overall quartet spin state of the complex. Then, ten geometries were randomly selected, each of which was used as the initial geometry (with its original atomic velocities preserved) for a subsequent MD simulation under the NVE condition with the overall spin switched manually to doublet (an analog of i10I-a(d)). Interestingly, the $\mathrm{CO}_{4}{ }^{\bullet-}$ intermediate was initially formed within the beginning 0.5 ps of the $N V E$ trajectories for all ten selected geometries. The resulting $\mathrm{CO}_{4}{ }^{\bullet-}$ was unstable against dissociation to the exchanged products $\mathrm{CO}_{2}$ and $\mathrm{O}_{2}{ }^{\bullet-}$. Fig. 6 shows a representative $N V E$ trajectory (only the first 2 ps duration is shown, all trajectories are available in ESI $\dagger$ ). As shown in Fig. 6a, $\mathrm{O}_{2}$ and $\mathrm{CO}_{2}{ }^{--}$ attracted one another upon the manual switch of spin from quartet to doublet; the $\mathrm{C}-\mathrm{O}$ distance (between the carbon atom of $\mathrm{CO}_{2}{ }^{--}$and the oxygen atoms of $\mathrm{O}_{2}$ ) was decreasing from 3-4 $\AA$ (0 ps) to $1.5-2 \AA$ (ca. 0.2 ps), yielding $\mathrm{CO}_{4}{ }^{\bullet-}$. Then, the $\mathrm{C}-\mathrm{O}$ distance was increased together with the OCO angle also increased from $\mathrm{ca} .140^{\circ}$ to linear, indicating that $\mathrm{CO}_{4}{ }^{--}$was dissociated into $\mathrm{CO}_{2}$ and $\mathrm{O}_{2}{ }^{\bullet-}$. The $\mathrm{CO}_{2}$ was weakly bound on the cluster surface in the remaining simulation time (total $5 \mathrm{ps).}$ Fig. $6 \mathrm{~b}$ shows the kinetic energies of the entire system (black) and some sub-systems, including the water cluster (red), $\mathrm{CO}_{2}$ (blue) and $\mathrm{O}_{2}$ (green), calculated based on the atomic velocities of the respective systems. A sharp increase of the total kinetic energy at the beginning of this NVE trajectory is attributed to the exothermic nature for the formation of the intermediate $\mathrm{CO}_{4}{ }^{\bullet-}$ and the exchanged products $\mathrm{O}_{2}{ }^{\bullet-}$ and $\mathrm{CO}_{2}$. This exothermic reaction energy was initially deposited onto the $\mathrm{CO}_{2}$ and $\mathrm{O}_{2}$ moieties, which were the species directly involved in the reaction coordinates. Then, the gained kinetic energies were rapidly redistributed to the water molecules within the next 1 ps. 

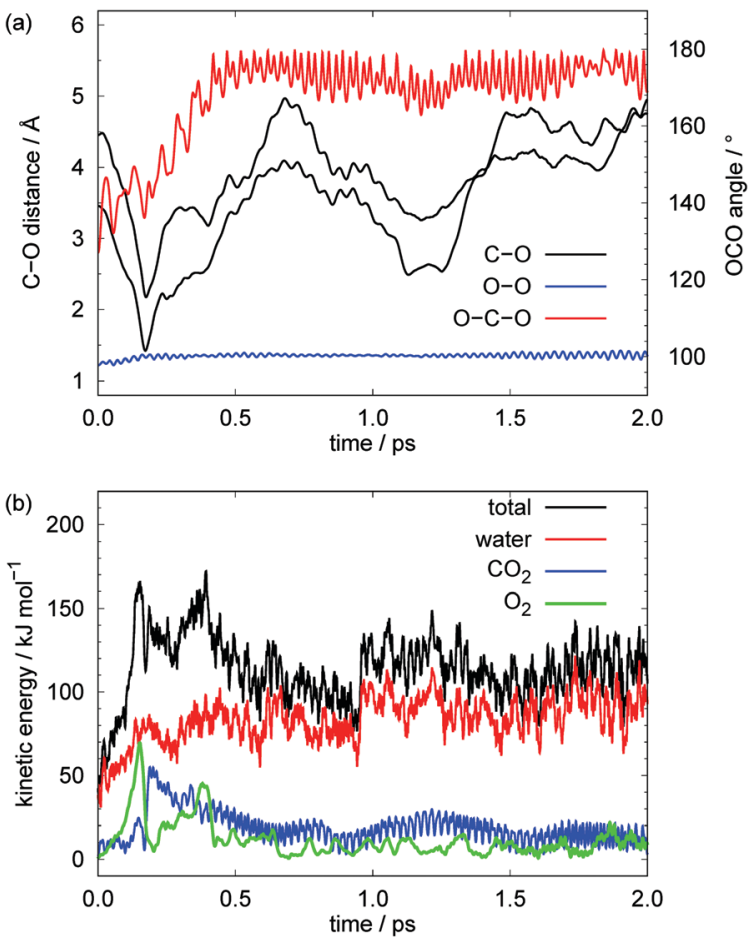

Fig. 6 A respective DFT-MD trajectory simulated under the NVE conditions for the exchange reaction $\mathrm{CO}_{2} \cdot-\left(\mathrm{H}_{2} \mathrm{O}\right)_{10}+\mathrm{O}_{2} \rightarrow \mathrm{O}_{2}{ }^{--}\left(\mathrm{H}_{2} \mathrm{O}\right)_{10}+\mathrm{CO}_{2}$. (a) The two $\mathrm{C}-\mathrm{O}$ distances between the $\mathrm{C}$ atom of $\mathrm{CO}_{2}$ and the two $\mathrm{O}$ atoms of $\mathrm{O}_{2}$ (black), the $\mathrm{O}-\mathrm{O}$ distance of $\mathrm{O}_{2}$ (blue) and the $\mathrm{OCO}$ angle of $\mathrm{CO}_{2}$ (red). (b) The kinetic energies of the entire system (black) and the sub-systems, including the water cluster (red), $\mathrm{CO}_{2}$ (blue) and $\mathrm{O}_{2}$ (green), determined from the atomic velocities of the respective systems.

Similar features were observed for all ten $N V E$ trajectories (ESI, $\dagger$ Fig. S9 and S10, ESI $\dagger$ ).

Such reaction energy redistribution is expected to be more efficient in the clusters with the size range of $n=50-130$. The effects of better thermobath were estimated with MD simulations under the NVT conditions at a temperature of $100 \mathrm{~K}$ using the initial geometries, $\left[\mathrm{O}_{2}, \mathrm{CO}_{2}{ }^{\bullet-}\left(\mathrm{H}_{2} \mathrm{O}\right)_{10}\right]$, and their atomic velocities same as those used for the NVE runs as shown in Fig. 6 . For these NVT simulations, the $\mathrm{CO}_{4}{ }^{\bullet-}$ intermediate was also produced and remained intact in the entire 5 ps duration for all (but one) trajectories (ESI, $\dagger$ Fig. S11). Elevating the temperature to $300 \mathrm{~K}$ also under the $N V T$ conditions, the $\mathrm{CO}_{4}{ }^{\bullet-}$ intermediate again dissociated to the exchanged products $\mathrm{O}_{2}{ }^{\bullet-}$ and $\mathrm{CO}_{2}$. A similar set of $N V T$ MD simulations at $100 \mathrm{~K}$ were also performed with initial geometries and atomic velocities taken from the ten NVE trajectories each at a point where the initially formed $\mathrm{CO}_{4}{ }^{\bullet-}$ intermediate was dissociating. As predicted, the complexes with exchanged products, $\left[\mathrm{CO}_{2}, \mathrm{O}_{2}{ }^{\bullet-}\left(\mathrm{H}_{2} \mathrm{O}\right)_{10}\right]$, were formed. In the MD approach under the $N V T$ conditions, the reaction energies of $\left[\mathrm{O}_{2}\right.$, $\left.\mathrm{CO}_{2}^{\bullet-}\left(\mathrm{H}_{2} \mathrm{O}\right)_{10}\right]$ to $\left[\mathrm{CO}_{4}{ }^{\bullet-}\left(\mathrm{H}_{2} \mathrm{O}\right)_{10}\right]$ then to $\left[\mathrm{CO}_{2}, \mathrm{O}_{2}{ }^{\bullet-}\left(\mathrm{H}_{2} \mathrm{O}\right)_{10}\right]$ were determined from the differences of their average potential energies, which are $-152 \pm 3 \mathrm{~kJ} \mathrm{~mol}^{-1}$ and $-142 \pm 9 \mathrm{~kJ} \mathrm{~mol}^{-1}$, respectively (the error bars are the standard deviations of the values from all trajectories). Our theoretical examinations, based on both geometry optimizations and molecular dynamics simulations, suggest that $\mathrm{CO}_{4}{ }^{\bullet-}\left(\mathrm{H}_{2} \mathrm{O}\right)_{n}$ is formed as a short-lived intermediate during the exchange reaction of $\mathrm{CO}_{2}{ }^{--}\left(\mathrm{H}_{2} \mathrm{O}\right)_{n}$ with $\mathrm{O}_{2}$.

\section{Discussion of the internal vs. surface solvation}

Due to limitations in computing resources, our quantum chemical calculations have been carried out on small cluster with only five or ten water molecules, in which all species, ions as well as neutrals, are at the surface. In the experiments, with cluster sizes up to 130 water molecules, internal solvation or at least a change in the hydrogen bonding network around the negative charge center must be considered. For $\mathrm{CO}_{2}{ }^{--}\left(\mathrm{H}_{2} \mathrm{O}\right)_{n}, n \leq 100$, a recent ab initio molecular dynamics study reports internal solvation for $n=50$ and $n=100 .^{71}$ However, Jungwirth and coworkers have recently shown that hydrated electrons at the surface of water differ very little from electrons solvated in bulk. ${ }^{20}$ These authors conclude that charges on the surface of water behave as almost fully hydrated species. This interpretation is in line with the early findings from cluster science by Castleman and coworkers ${ }^{66}$ that the binding energy of a water molecule to an ionic cluster $\mathrm{X}^{ \pm}\left(\mathrm{H}_{2} \mathrm{O}\right)_{n}$ converges very quickly, i.e. $n<10$. This means that the contribution of the ion-water interaction to the overall hydration enthalpy is already accounted for in very small clusters. Changes associated with the transition from surface to internal solvation can be expected to be smaller than error limits of the thermochemical values reported in the present study.

\section{Conclusions}

With a series of experiments at different temperatures and cluster sizes, we established reliable enthalpies for the three studied reactions, which are consistent within error limits. Quantum chemical calculations of the charge exchange reaction potential energy surface corroborate the prediction by Weber that the reaction proceeds through a $\mathrm{CO}_{4}{ }^{\bullet-}$ intermediate. Our previous interpretation of a non-ergodic component in the charge exchange reaction between $\mathrm{CO}_{2}{ }^{\bullet-}$ and $\mathrm{O}_{2}$ has been shown to be wrong, it was based on one unreliable data set. The newly derived hydration enthalpies of $\mathrm{CO}_{2}{ }^{\bullet-}$ and $\mathrm{O}_{2}{ }^{\bullet-}$ are close to previous estimates by Posey et al. Since each value is based on more than ten data sets in the present study, these thermochemical values are more reliable.

\section{Acknowledgements}

Financial support from the Deutsche Forschungsgemeinschaft, Grant No. BE2505/4-3 (A. A., M. K. B.), is gratefully acknowledged. C. K. S. thanks City University of Hong Kong (CityU) for financial support (Project No. 7004401). W. K. T. acknowledges Chow Yei Ching School of Graduate Studies of CityU for his postgraduate studentship and scholarship.

\section{References}

1 H. Haberland, H. Langosch, H. G. Schindler and D. R. Worsnop, J. Phys. Chem., 1984, 88, 3903.

2 H. Haberland, C. Ludewigt, H. G. Schindler and D. R. Worsnop, J. Chem. Phys., 1984, 81, 3742. 
3 H. Haberland, H. G. Schindler and D. R. Worsnop, Ber. Bunsen-Ges., 1984, 88, 270.

4 J. V. Coe, G. H. Lee, J. G. Eaton, S. T. Arnold, H. W. Sarkas, K. H. Bowen, C. Ludewigt, H. Haberland and D. R. Worsnop, J. Chem. Phys., 1990, 92, 3980.

5 G. H. Lee, S. T. Arnold, J. G. Eaton, H. W. Sarkas, K. H. Bowen, C. Ludewigt and H. Haberland, Z. Phys. D: At., Mol. Clusters, 1991, 20, 9.

6 J. V. Coe, S. M. Williams and K. H. Bowen, Int. Rev. Phys. Chem., 2008, 27, 27.

7 B. C. Garrett, D. A. Dixon, D. M. Camaioni, D. M. Chipman, M. A. Johnson, C. D. Jonah, G. A. Kimmel, J. H. Miller, T. N. Rescigno, P. J. Rossky, S. S. Xantheas, S. D. Colson, A. H. Laufer, D. Ray, P. F. Barbara, D. M. Bartels, K. H. Becker, H. Bowen, S. E. Bradforth, I. Carmichael, J. V. Coe, L. R. Corrales, J. P. Cowin, M. Dupuis, K. B. Eisenthal, J. A. Franz, M. S. Gutowski, K. D. Jordan, B. D. Kay, J. A. LaVerne, S. V. Lymar, T. E. Madey, C. W. McCurdy, D. Meisel, S. Mukamel, A. R. Nilsson, T. M. Orlando, N. G. Petrik, S. M. Pimblott, J. R. Rustad, G. K. Schenter, S. J. Singer, A. Tokmakoff, L. S. Wang, C. Wittig and T. S. Zwier, Chem. Rev., 2005, 105, 355.

8 K. R. Asmis, G. Santambrogio, J. Zhou, E. Garand, J. Headrick, D. Goebbert, M. A. Johnson and D. M. Neumark, J. Chem. Phys., 2007, 126, 191105.

9 P. Ayotte, C. G. Bailey, J. Kim and M. A. Johnson, J. Chem. Phys., 1998, 108, 444.

10 P. Ayotte and M. A. Johnson, J. Chem. Phys., 1997, 106, 811.

11 P. J. Campagnola, D. J. Lavrich, M. J. Deluca and M. A. Johnson, J. Chem. Phys., 1991, 94, 5240.

12 N. I. Hammer, J. W. Shin, J. M. Headrick, E. G. Diken, J. R. Roscioli, G. H. Weddle and M. A. Johnson, Science, 2004, 306, 675.

13 L. A. Posey, P. J. Campagnola, M. A. Johnson, G. H. Lee, J. G. Eaton and K. H. Bowen, J. Chem. Phys., 1989, 91, 6536.

14 A. E. Bragg, J. R. R. Verlet, A. Kammrath, O. Cheshnovsky and D. M. Neumark, Science, 2004, 306, 669.

15 A. T. Shreve, T. A. Yen and D. M. Neumark, Chem. Phys. Lett., 2010, 493, 216.

16 J. R. R. Verlet, A. E. Bragg, A. Kammrath, O. Cheshnovsky and D. M. Neumark, Science, 2005, 307, 93.

17 R. M. Young and D. M. Neumark, Chem. Rev., 2012, 112, 5553.

18 R. M. Young, M. A. Yandell, S. B. King and D. M. Neumark, J. Chem. Phys., 2012, 136, 94304.

19 B. Abel, U. Buck, A. L. Sobolewski and W. Domcke, Phys. Chem. Chem. Phys., 2012, 14, 22.

20 F. Uhlig, O. Marsalek and P. Jungwirth, J. Phys. Chem. Lett., 2013, 4, 338.

21 L. A. Posey, M. J. Deluca, P. J. Campagnola and M. A. Johnson, J. Phys. Chem., 1989, 93, 1178.

22 S. T. Arnold, R. A. Morris, A. A. Viggiano and M. A. Johnson, J. Phys. Chem., 1996, 100, 2900.

23 O. P. Balaj, C. K. Siu, I. Balteanu, M. K. Beyer and V. E. Bondybey, Chem. - Eur. J., 2004, 10, 4822.

24 R. F. Höckendorf, O. P. Balaj, C. van der Linde and M. K. Beyer, Phys. Chem. Chem. Phys., 2010, 12, 3772.
25 W. A. Donald, R. D. Leib, J. T. O’Brien and E. R. Williams, Chem. - Eur. J., 2009, 15, 5926.

26 W. A. Donald, R. D. Leib, J. T. O’Brien, A. I. S. Holm and E. R. Williams, Proc. Natl. Acad. Sci. U. S. A., 2008, 105, 18102.

27 R. F. Höckendorf, O. P. Balaj and M. K. Beyer, Phys. Chem. Chem. Phys., 2011, 13, 8924.

28 R. F. Höckendorf, Q. Hao, Z. Sun, B. S. Fox-Beyer, Y. Cao, O. P. Balaj, V. E. Bondybey, C.-K. Siu and M. K. Beyer, J. Phys. Chem. A, 2012, 116, 3824.

29 A. Akhgarnusch, R. F. Höckendorf and M. K. Beyer, J. Phys. Chem. A, 2015, 119, 9978.

30 A. Akhgarnusch, R. F. Höckendorf, Q. Hao, K. P. Jäger, C.-K. Siu and M. K. Beyer, Angew. Chem., Int. Ed., 2013, 52, 9327.

31 R. F. Höckendorf, K. Fischmann, Q. Hao, C. van der Linde, O. P. Balaj, C.-K. Siu and M. K. Beyer, Int. J. Mass Spectrom., 2013, 354-355, 175.

32 R. F. Höckendorf, C.-K. Siu, C. van der Linde, O. P. Balaj and M. K. Beyer, Angew. Chem., Int. Ed., 2010, 49, 8257.

33 C. van der Linde, S. Hemmann, R. F. Höckendorf, O. P. Balaj and M. K. Beyer, J. Phys. Chem. A, 2013, 117, 1011.

34 C. van der Linde, R. F. Höckendorf, O. P. Balaj and M. K. Beyer, Chem. - Eur. J., 2013, 19, 3741.

35 I. Herber, W.-K. Tang, H.-Y. Wong, T.-W. Lam, C.-K. Siu and M. K. Beyer, J. Phys. Chem. A, 2015, 119, 5566.

36 M. Allemann, H. Kellerhals and K. P. Wanczek, Int. J. Mass Spectrom. Ion Processes, 1983, 46, 139.

37 P. Kofel, M. Allemann, H. Kellerhals and K. P. Wanczek, Int. J. Mass Spectrom. Ion Processes, 1986, 72, 53.

38 C. Berg, T. Schindler, G. Niedner-Schatteburg and V. E. Bondybey, J. Chem. Phys., 1995, 102, 4870.

39 O. P. Balaj, C. B. Berg, S. J. Reitmeier, V. E. Bondybey and M. K. Beyer, Int. J. Mass Spectrom., 2009, 279, 5.

40 V. E. Bondybey and J. H. English, J. Chem. Phys., 1981, 74, 6978.

41 T. G. Dietz, M. A. Duncan, D. E. Powers and R. E. Smalley, J. Chem. Phys., 1981, 74, 6511.

42 S. Maruyama, L. R. Anderson and R. E. Smalley, Rev. Sci. Instrum., 1990, 61, 3686.

43 T. Schindler, C. Berg, G. Niedner-Schatteburg and V. E. Bondybey, Ber. Bunsen-Ges., 1992, 96, 1114.

44 B. S. Fox, M. K. Beyer and V. E. Bondybey, J. Phys. Chem. A, 2001, 105, 6386.

45 O. Hampe, T. Karpuschkin, M. Vonderach, P. Weis, Y. M. Yu, L. B. Gan, W. Klopper and M. M. Kappes, Phys. Chem. Chem. Phys., 2011, 13, 9818.

46 S. W. Lee, P. Freivogel, T. Schindler and J. L. Beauchamp, J. Am. Chem. Soc., 1998, 120, 11758.

47 T. Schindler, C. Berg, G. Niedner-Schatteburg and V. E. Bondybey, Chem. Phys. Lett., 1996, 250, 301.

48 P. D. Schnier, W. D. Price, R. A. Jockusch and E. R. Williams, J. Am. Chem. Soc., 1996, 118, 7178.

49 M. Sena and J. M. Riveros, Rapid Commun. Mass Spectrom., 1994, 8, 1031.

50 R. C. Dunbar, Mass Spectrom. Rev., 2004, 23, 127.

51 C. Hock, M. Schmidt, R. Kuhnen, C. Bartels, L. Ma, H. Haberland and B. von Issendorff, Phys. Rev. Lett., 2009, 103, 73401. 
52 W. A. Donald, R. D. Leib, M. Demireva, B. Negru, D. M. Neumark and E. R. Williams, J. Phys. Chem. A, 2011, 115, 2.

53 R. D. Leib, W. A. Donald, M. F. Bush, J. T. O'Brien and E. R. Williams, J. Am. Chem. Soc., 2007, 129, 4894.

54 M. J. Frisch, G. W. Trucks, H. B. Schlegel, G. E. Scuseria, M. A. Robb, J. R. Cheeseman, G. Scalmani, V. Barone, B. Mennucci, G. A. Petersson, H. Nakatsuji, M. Caricato, X. Li, H. P. Hratchian, A. F. Izmaylov, J. Bloino, G. Zheng, J. L. Sonnenberg, M. Hada, M. Ehara, K. Toyota, R. Fukuda, J. Hasegawa, M. Ishida, T. Nakajima, Y. Honda, O. Kitao, H. Nakai, T. Vreven, J. J. A. Montgomery, J. E. Peralta, F. Ogliaro, M. Bearpark, J. J. Heyd, E. Brothers, K. N. Kudin, V. N. Staroverov, R. Kobayashi, J. Normand, K. Raghavachari, A. Rendell, J. C. Burant, S. S. Iyengar, J. Tomasi, M. Cossi, N. Rega, J. M. Millam, M. Klene, J. E. Knox, J. B. Cross, V. Bakken, C. Adamo, J. Jaramillo, R. Gomperts, R. E. Stratmann, O. Yazyev, A. J. Austin, R. Cammi, C. Pomelli, J. W. Ochterski, R. L. Martin, K. Morokuma, V. G. Zakrzewski, G. A. Voth, P. Salvador, J. J. Dannenberg, S. Dapprich, A. D. Daniels, O. Farkas, J. B. Foresman, J. V. Ortiz, J. Cioslowski and D. J. Fox, Gaussian 09, Revision D.01, Gaussian, Inc., Wallingford CT, 2013.

55 J. VandeVondele, M. Krack, F. Mohamed, M. Parrinello, T. Chassaing and J. Hutter, Comput. Phys. Commun., 2005, 167, 103.

56 S. Goedecker, M. Teter and J. Hutter, Phys. Rev. B: Condens. Matter Mater. Phys., 1996, 54, 1703.

57 J. VandeVondele and J. Hutter, J. Chem. Phys., 2007, 127, 114105. 58 S. Grimme, J. Comput. Chem., 2006, 27, 1787.

59 S. Grimme, J. Antony, S. Ehrlich and H. Krieg, J. Chem. Phys., 2010, 132, 154104.
60 S. Grimme, S. Ehrlich and L. Goerigk, J. Comput. Chem., 2011, 32, 1456.

61 G. J. Martyna and M. E. Tuckerman, J. Chem. Phys., 1999, 110, 2810.

62 S. Nosé, J. Chem. Phys., 1984, 81, 511.

63 P. Langevin, Ann. Chim. Phys., 1905, 5, 245.

64 L. Bass, T. Su, W. J. Chesnavich and M. T. Bowers, Chem. Phys. Lett., 1975, 34, 119.

65 G. Kummerlöwe and M. K. Beyer, Int. J. Mass Spectrom., 2005, 244, 84.

66 N. Lee, R. Keesee and A. Castleman, J. Colloid Interface Sci., 1980, 75, 555.

67 J. Mikosch, M. Weidemüller and R. Wester, Int. Rev. Phys. Chem., 2010, 29, 589.

68 C. J. Tsai and K. D. Jordan, J. Phys. Chem., 1993, 97, 5208.

69 S. Yoo and S. S. Xantheas, in Handbook of computational chemistry, ed. J. Leszczynski, Springer Science + Business Media B.V, Dordrecht, New York, 2012, pp. 761-792.

70 P. Miró and C. J. Cramer, Phys. Chem. Chem. Phys., 2013, 15, 1837.

71 P. Liu, J. Zhao, J. Liu, M. Zhang and Y. Bu, J. Chem. Phys., 2014, 140, 44318.

72 M. Knapp, O. Echt, D. Kreisle, T. D. Märk and E. Recknagel, Chem. Phys. Lett., 1986, 126, 225.

73 R. N. Compton, P. W. Reinhardt and C. D. Cooper, J. Chem. Phys., 1975, 63, 3821.

74 H. Shiraishi, G. R. Sunaryo and K. Ishigure, J. Phys. Chem., 1994, 98, 5164.

75 K. M. Ervin, W. Anusiewicz, P. Skurski, J. Simons and W. C. Lineberger, J. Phys. Chem. A, 2003, 107, 8521.

76 M. Arshadi and P. Kebarle, J. Phys. Chem., 1970, 74, 1483. 